\title{
RECEPCIÓN TEMPRANA DE LA TEORÍA DE LA DERIVA CONTINENTAL Y SU COMPETENCIA CON LAS TEORÍAS RIVALES
}

Carlos Pérez-Malváez, Alfredo Bueno H.

Museo de Zoología, FES Zaragoza, UNAM, Méjico

Juan J. Morrone

Museo de Zoología, Facultad de Ciencias, UNAM, Méjico

\begin{abstract}
«Las especies actuales de dos continentes son ciertamente distintas, pero los géneros y familias siguen siendo los mismos; y lo que hoy es género o familia, fue especie en el pasado. Es decir, que el parentesco de fauna y flora actuales lleva a la conclusión de que estas faunas y floras fueron idénticas en el pasado y, por tanto, que debe haber existido un intercambio, lo cual sólo puede imaginarse contando con una conexión terrestre muy extensa. Sólo tras la rotura de la conexión continental se separaron las faunas y floras en las diversas especies actuales».
\end{abstract}

Wegener (1930)

\section{RESUMEN}

Alfred Lothar Wegener propuso la teoría de la deriva continental en 1912. Wegener ciertamente pensó que el desplazamiento explicaba mas datos paleontológicos y geofísicos que cualquiera de los programas de investigación establecidos. Desde luego, la gran virtud de la teoría de la deriva fue su gran capacidad de síntesis. Wegener recurrió a la información que provenía de la Geología, Geofísica, Paleontología y Paleoclimatología.

PALABRAS CLAVE: Alfred Lothar Wegener, deriva continental, geología. 


\section{SUMMARY}

In 1912 Alfred Lothar Wegener proposed the theory of the continental drift. Wegener thought that the displacement explained more paleontological and geophysical data than any other rival program. The great virtue of the drift theory resided in their great capacity of synthesis. Wegener appealed to the information provided by the Geology, Paleontology and Paleoclimatology.

KEY WORDS: Alfred Lothar Wegener, continental drift, geology.

Cuando Alfred L. Wegener (1880-1930) propuso la teoría de la deriva continental, había otros dos modelos en boga entre la comunidad geofísica internacional: el contraccionismo y el permanentismo. El primero consideraba que la Tierra se ha contraído periódicamente desde su origen, con el resultado de que el fondo oceánico y los continentes se han intercambiado a través de la historia del planeta. De acuerdo con el segundo, luego de una contracción original del material de los continentes y el fondo de los océanos según sus densidades, los océanos y continentes han permanecido siempre iguales. El programa de investigación de la deriva resultó radical y novedoso respecto de los modelos contraccionista y permanentista. La teoría de Wegener implicaba el movimiento horizontal de los continentes a gran escala. El punto esencial es que los geofísicos que adherían los otros dos programas de investigación rechazaron este desplazamiento de las masas continentales, ya que ambos coincidían en que los grandes cambios en el contorno de la superficie de la Tierra solo implicaban desplazamientos verticales ${ }^{1}$.

Nuestro objetivo es analizar y discutir las ideas de Wegener con relación a las teorías rivales con las que se enfrentó, así como las reacciones que la teoría de la deriva continental generó entre la comunidad de geólogos y biogeógrafos.

\section{EL PROGRAMA DE INVESTIGACIÓN CONTRACCIONISTA}

Muchos paleontólogos, zoólogos y botánicos habían concluido que los continentes separados hoy por anchos océanos debieron tener en el pasado conexiones terrestres, a través de las cuales se efectuaron, sin impedimentos, intercambios de fauna y flora terrestres. Esto lo evidenciaban los numerosos casos de especies idénticas que habían vivido en el pasado a ambos lados del

1 Frankel, H. (1979), «The career of continental drift theory: an application of Imre Lakatos analysis of scientific growth to the rise of drift theory», Stud. Hist. Phil. Sci., 10, pp. 21-66. 
océano y era impensable suponerlos orígenes separados en lugares diferentes. Wegener consideraba que, en muchos casos, los antiguos puentes continentales se habían propuesto con base en indicios muy pobres y sin haber sido confirmados por evidencia empírica. La hipótesis de que existieron continentes que se habían hundido se basaba en la doctrina de la contracción de la Tierra ${ }^{2}$.

Murchison, Sedgwick, Elie de Beaumont y Lyell murieron entre 1871 y 1874, mientras que Prévost, De la Beche, Buckland y d'Orbigny, lo habían hecho unos 20 años antes. Así, hacia fines del siglo XIX, los fundadores de la geología ya habían fallecido, y una nueva concepción de la Tierra comenzaba a gestarse. E. Suess fue el primero que manifestó interés por los movimientos actuales de la corteza externa de la Tierra. Aunque parezca extraño, el primer fenómeno que atrajo su atención fue el Diluvio Universal. Luego de analizar en detalle algunos textos mesopotámicos que relataban un evento similar, Suess propuso que un fuerte sismo asociado con un huracán había empujado las aguas del mar hacia arriba, a través del valle del Éufrates. Su interpretación difería de la versión bíblica, según explicaba, en que esta última fue escrita por testigos situados muy lejos del evento, quienes distorsionaron la narración. Concluyó que el diluvio fue un evento local y que el Monte Ararat no se refería, en realidad, a la cumbre generalmente así llamada, sino que se había confundido con un pequeño cerro homónimo.

Suess intentaba mostrar que los movimientos regulares de la corteza de la Tierra podían ser explicados por el uniformitarismo (doctrina según la cual los mismos procesos que actúan en el presente son los que han operado en el pasado). Sin embargo, aceptaba que excepcionalmente procesos poderosos, como los propuestos por el catastrofismo (que implica procesos radicalmente diferentes a los actuales), podían también contribuir a formar la faz de la Tierra. En el transcurso de una solidificación y una contracción progresivas a partir de una masa en fusión, los materiales rocosos más ligeros habían ido subiendo hacia la superficie, provocando la aparición de rocas ígneas de tipo granítico y metamórficas, asociadas con sedimentos. Se designaban en conjunto por el término sal (que más tarde se cambió a sial), porque eran relativamente ricos en silicatos de aluminio con sodio y potasio. Subyacentes al sial, se encontraban rocas más densas llamadas conjuntamente sima, las cuales eran ricas en silicatos de hierro, calcio y magnesio. Las cordilleras se habían producido mediante contracción, de forma análoga a las arrugas que se forman en una manzana que se va secando. A mayor escala, una presión gene-

2 Wegener, A. (1929), The origin of continents and oceans, Nueva York Dover Publications. 
ral de arqueamiento causó el colapso y la subsidencia de determinados sectores de la superficie de la Tierra, lo que originó los océanos, mientras que los continentes permanecían emergidos como bloques sin fallas. Ciertas áreas continentales se hundieron más rápidamente que otras adyacentes $\mathrm{y}$, por lo tanto, fueron inundadas por el mar, mientras que las partes del fondo oceánico estabilizadas temporalmente en otras épocas emergieron de nuevo como tierra firme. En esos años se encontraron abundantes casos de fósiles casi idénticos, distribuidos en distintos continentes, a ambos lados del océano, lo que se tomaba como prueba de antiguas conexiones terrestres, a través de lo que ahora eran las profundidades oceánicas. A no ser que en el pasado hubiera habido esos puentes terrestres transoceánicos, las similitudes reconocidas ampliamente en la vida orgánica eran inexplicables a la luz de la teoría darwiniana de la evolución ${ }^{3}$.

E. Suess llamó Gondwana al antiguo continente que habría incluido África central y meridional, Madagascar y la India, utilizando el nombre de la fauna paleozoica Gondwana común a estas áreas. La utilización más general de la expresión Gondwana se ha extendido hasta abarcar también Australia, América del Sur y la Antártida. En 1887 M. Neumayr postuló la existencia de un continente que se extendía desde América del Sur a África y que enviaba una rama hacia el noreste de la India, lo cual fue apoyado por W.T. Blanford en 1890. Sin embargo, Suess fue quien posteriormente sintetizó los datos y le confirió a esta masa el nombre de tierra Gondwana. Asimismo, Suess propuso la expresión eustático para referirse a los ascensos y descensos del nivel del mar a escala mundial que podían deducirse a partir de la información estratigráfica de las sucesivas transgresiones y regresiones marinas en los continentes. Atribuía las regresiones a la subsidencia de las cuencas oceánicas, mientras que las transgresiones se debían al rellenado parcial de dichas cuencas por sedimentos aportados por los continentes ${ }^{4}$. De esta manera el agua de los continentes iría desapareciendo a medida que aumentaba la profundidad de los océanos o, por el contrario, sería transportada a estos continentes como consecuencia de la sedimentación sobre el fondo oceánico. Suess consideró que los movimientos eustáticos pueden actuar sobre la vida: «...ya favoreciendo las migraciones terrípetas ya, inversamente, la vuelta a la mar, y pueden también, cuando son repentinas, aniquilar la vida en toda la zona litoral, pero sobre ese extremo, carecemos de observaciones ciertas y tenemos que

3 Suess, E. (1930), La Faz de la Tierra, versión española de Pedro de Novo y F. Chicarro, Madrid, imp. de Ramona, t. IV, pp. 409-447.

4 Du TolT, A. L. (1937), Our wandering continents: An hypothesis of continental drifting, Londres, Oliver and Boyd, pp. 1-57, 317-332 
limitarnos a interpretar los fenómenos biológicos... Aunque la vida no estaba exenta en aquellos parajes de la influencia de cambios climatológicos, ni de trastornos en la economía de los seres producidos por inmigraciones extrañas y aun de sumersión total bajo las aguas marinas, pudieron desarrollarse allí sucesivamente las distintas floras donde las perturbaciones que afectan a la vida eran menores que en los demás sitios; por esto los llamamos asilos. De allí partieron probablemente colonias nuevas para repoblar las tierras después de los tiempos de grandes trastornos; por eso hemos comparado tales asilos a la isla paradisíaca de Linneo... $\rangle^{5}$.

Después de la imponente síntesis que supuso la teoría de la contracción para la geología, se fueron acumulando dudas sobre la corrección básica de la teoría. La hipótesis de que todos los levantamientos son solo aparentes, y que en realidad consisten en retrasos en la tendencia general de la corteza a moverse hacia el centro de la Tierra, fue rebatida al detectarse levantamientos absolutos. La interpretación de las cadenas de montañas como arrugas superficiales debidas a la contracción del interior terrestre, llevó a la inaceptable consecuencia de que la presión tenía que transmitirse en el interior de la corteza terrestre a lo largo de distancias equivalentes a semicírculos máximos. $\mathrm{La}$ suposición básica de que la Tierra se está enfriando quedó en entredicho tras el descubrimiento del radio. Este elemento, cuya desintegración genera calor continuamente, está contenido en cantidades mensurables en las rocas de la corteza que nos son accesibles, y las numerosas medidas efectuadas indican que si el interior de la Tierra contuviese igual cantidad de radio, el calor producido debería ser incomparablemente mayor que el transportado hacia afuera. De las numerosas objeciones contra la teoría de la contracción destaca una. Cuantificando de la gravedad, la geofísica ha concluido que la corteza flota en equilibrio isostático sobre un sustrato denso y viscoso: a este estado se lo llama isostasia. La isostasia es el equilibrio hidrostático regido por el principio de Arquímedes, por el que el peso de un cuerpo sumergido iguala al peso del fluido desalojado ${ }^{6}$.

\section{ISOSTASIA Y ESTRUCTURA DE LA CORTEZA}

La teoría de la isostasia sostiene que la corteza terrestre flota en equilibrio isostático sobre un denso sustrato viscoso, formando el fondo de los océanos.

5 SuEss, E. (1930), t.,IV, pp. 427-428.

6 Wegener, A. (1929), The origin of continents and oceans, Nueva York, Dover Publications. 
Si los continentes son barcazas sobre su sustrato, no pueden hundirse en el fondo del océano a menos que hayan sido sobrecargados. El concepto de isostasia se basa en una serie de observaciones hechas durante el siglo XIX en la India, donde las mediciones del arco meridional entre dos ciudades revelaron una discrepancia entre las medidas astronómicas y geofísicas. Otras observaciones importantes fueron los valores de la gravedad en distintos puntos de la superficie de la Tierra.

Cuando se calcula el valor de la gravedad en un punto a cierta altura, hay que tener en cuenta también la masa de material entre dicho punto y el nivel del mar. Esta corrección es importante cuando se calculan las anomalías de la gravedad, denominadas anomalías de Bouguer en memoria del geofísico belga P. Bouguer (1698-1758), que calculó el efecto de esta masa al medir la gravedad en dos ciudades del Ecuador. Aun corrigiendo este efecto, siguen existiendo anomalías entre los valores observados y teóricos de la gravedad. La explicación de estas anomalías es que los materiales en el interior de la Tierra no son homogéneos, sino que existen masas en diversos puntos con densidades mayores o menores que las de las rocas circundantes. Si la gravedad observada es mayor que la teórica, la anomalía es positiva, y en el caso contrario, negativa. Si bajo un punto de la superficie de la Tierra hay una concentración de material muy denso, éste producirá un aumento de la atracción de la gravedad y, en consecuencia, una anomalía positiva. Por el contrario, los materiales ligeros causan anomalías negativas. De esta forma, las anomalías de la gravedad se pueden usar para descubrir la existencia de minerales debajo de la superficie de la Tierra, y también para conocer la estructura de la corteza terrestre, en especial para determinar aquellos sitios donde la corteza es más delgada o más gruesa de lo normal. Es decir, las anomalías reflejan el espesor de la corteza terrestre, y se puede afirmar que el estudio de las anomalías ha revelado valores negativos sobre las montañas y positivos sobre los océanos y zonas costeras. Este patrón fue descubierto a mediados del siglo pasado por Pratt y Airy, quienes hicieron medidas astronómicas en la India, cerca de los montes Himalayas.

J. H. Pratt (1800-1871), quien ocupaba el cargo eclesiástico de archidiácono de Calcuta, interpretó las diferencias de las medidas astronómicas de la India como debidas al efecto ejercido por los Himalayas en la dirección de la línea vertical. La sacudida de la plomada, que bajo condiciones normales apunta hacia el centro de la gravedad de la Tierra, se desvía por la vecindad de las masas atrayentes. Pratt hizo cálculos apropiados y encontró, para su sorpresa, que los Himalayas tienden a producir una gran deflexión. Los escritos de Pratt despertaron el interés de G. B. Airy (1801-1893), astrónomo real 
del Reino Unido, quien imaginó que la corteza flotaba en un fluido de alta densidad, como una balsa de troncos sobre el agua. Airy indicó que los troncos que se levantan sobre la superficie también se sumergen profundamente en el fluido, siguiendo el principio de Arquímedes, por lo cual el peso del cuerpo inmerso es igual al fluido desplazado. De esta forma, asumió que las raíces de la barcaza de la corteza están presentes debajo de los Himalayas y el Tíbet, extendiéndose dentro del fluido que la sostiene y compensando, a cierta extensión, la deflexión producida por la masa de las montañas. En 1859, Pratt refutó la hipótesis de Airy, al afirmar que la corteza es tan densa como la base fluida, ya que ambas consisten del mismo material, enfriándose y contrayéndose, lo cual provoca el levantamiento de la corteza. En estos términos, la contracción es menos fuerte en la región de las montañas que en las zonas bajas; la densidad puede ser baja en las cordilleras montañosas, compensándose con una mayor altitud. En relación con la polémica Pratt-Airy, Wegener escribió: «La interpretación correcta se podría encontrar uniendo ambas concepciones. En el caso de las cadenas de montañas nos encontramos con una corteza ligera engrosada en el sentido de Airy; pero cuando consideramos la zona de transición entre los bloques continentales y los fondos oceánicos es cuestión de diferencias en el tipo de materiales en el sentido de Pratt» ${ }^{7}$.

Wegener entendió que si los continentes no tienen la misma composición que los océanos, no puede haber intercambio entre la corteza terrestre como Suess asume. Más aún, la isostasia implica movimientos verticales de la corteza. Se sabe que Escandinavia se hundió bajo el peso del hielo durante la glaciación del pleistoceno, y después ha rebotado en sentido contrario, durante el calentamiento del tiempo posglacial. Similarmente, cuando la corteza continental se adelgaza por la erosión, se hace ligera y asciende ${ }^{8}$.

\section{LOS PUENTES INTERCONTINENTALES}

A principios del siglo XX se creía que existieron puentes de tierra entre los continentes actuales, explicando así la fauna y flora comunes a continentes separados por un océano. Se plantearon numerosos puentes: entre África y Brasil hubo uno llamado Arqueo-Helenis, mientras que Europa y América del Norte se unían por la Arqueo-Atlántida. Pequeños puentes de tierra a través

7 WegENER, A. (1929), p. 43.

8 Gohau, G. (1990), A history of geology, New Brunswick and London,Rutgers University Press, pp. 187-200. 
del océano Indico unieron Madagascar e India y la India con Australia. Sobre la base de las identidades o semejanzas de flora y fauna entre los distintos continentes, la mayoría de los especialistas consideraban necesaria una conexión terrestre, o en el caso de los organismos neríticos, alguna clase de vínculo entre las plataformas continentales submarinas ${ }^{9}$. La concordancia biótica se acentuaba en el caso de las conexiones mesozoicas entre Brasil y África, Australia y África-India, y Suráfrica-Madagascar e India. Wegener citaba como ejemplos el pequeño reptil Mesosaurus, conocido solamente a partir del pérmico en Suráfrica y Brasil, y la planta Glossopteris, muy difundida a fines del paleozoico, pero confinada a los continentes del sur. El argumento paleontológico resulta de la comparación de los restos fósiles entre los llamados supercontinentes Laurasia y Gondwana. La flora y fauna de Gondwana eran pobres en especies de clima frío, mientras que los restos de la flora y fauna de Laurasia era notablemente ricos en especies tropicales. Esto se atribuyó a que en el carbonífero tuvo lugar una notable diferenciación climática que originó floras de carácter muy distinto.

Wegener descartaba la idea de los puentes intercontinentales, pues la corteza de la Tierra está compuesta de rocas mucho menos densas que el material del interior. Así, la improbabilidad esencial de los puentes de tierra hundidos se expresaba en términos de equilibrio isostático. Si las rocas de baja densidad de los desaparecidos puentes hubieran sido forzadas, de alguna forma, a sumergirse en el fondo marino más denso, los puentes tenderían a levantarse de nuevo. Sin embargo, ninguno de los hipotéticos puentes de tierra han vuelto a emerger. Por lo tanto, se hace necesario postular la existencia de alguna fuerza colosal, no especificada, que siga manteniendo los puentes sumergidos. La existencia de tal fuerza es improbable. A menos que de entrada se quisiera descartar los datos fósiles, Wegener concluyó que el único medio razonable para explicar las similitudes bióticas intercontinentales era la deriva de los propios continentes.

Los contraccionistas, inicialmente, hicieron énfasis en la paleontología y la biología a expensas de la geofísica y, por lo tanto, cabría esperar que plantearan hipótesis auxiliares en un intento de explicar los datos olvidados de los geofísicos. Este es precisamente el comportamiento de Chamberlin y Jeffreys, quienes fueron los más importantes defensores del contraccionismo después de Suess. El programa de investigación contraccionista afrontó dos serios problemas derivados de las investigaciones geofísicas. El primero, como ya hemos señalado, fue el descubrimiento de la radioactividad. En consecuencia, los contrac-

9 Hallam, A. (1972), «La deriva continental y el registro fósi», en WiLsON, E. (ed.), Ecología, evolución y biología de poblaciones, Barcelona, Selecciones de Scientific American, Omega, pp. 81-90. 
cionistas necesitaron una nueva explicación para la contracción de la Tierra. En segundo lugar, tuvieron que hacer las paces con el principio isostático. T. C. Chamberlin se anticipó a los contraccionistas al establecer una hipótesis que resolvía ambos problemas, y ampliaba así los hechos que el contraccionismo podía explicar. En 1904 Chamberlin unió fuerzas con el astrónomo F. R. Moulton, y formularon su hipótesis planetaria. En esos años, Chamberlin se centró en los aspectos geológicos de la hipótesis. La hipótesis ChamberlinMoulton suponía que la Tierra se había formado de la materia sólida del Sol, a través de una colisión cercana con una estrella fugaz, seguida por la formación de una Tierra gaseosa o sólida. Propuso que la Tierra se construyó a través del aumento de partículas, o planetesimales, que se han venido contrayendo desde su formación. Sin embargo, la contracción fue causada por las fuerzas gravitacionales más que por el enfriamiento de la Tierra. La hipótesis planetesimal se ajusta mucho mejor con el principio isostático y la radioactividad. Queda salvado el principio isostático, ya que los planetesimales se han reordenado solos con respecto a sus densidades: las partes más densas se movieron hacia el centro de la tierra, mientras las menos densas flotaron hacia la superficie. Así, el programa de investigación del contraccionismo se fue a flote una vez más al asimilar sus críticas ${ }^{10}$.

\section{LA OBJECIÓN GEOFÍSICA A LA TEORÍA DE LA DERIVA}

Uno de los críticos más duros de la hipótesis de la deriva continental fue Harold Jeffreys, para quien la corteza continental era suficientemente fuerte como para soportar el monte Everest, y la corteza oceánica tan fuerte como para mantener profundas fosas. Las críticas de Jeffreys fueron el punto de partida de la oposición, quizá más formidable, que hubo de soportar Wegener. Se trata de lo que podría llamarse la escuela geofísica de la Tierra ultrasólida, establecida en Gran Bretaña y los Estados Unidos. Los geofísicos adherentes a esta teoría creían que podían demostrar, de manera definitiva, que la Tierra poseía una rigidez tal que impedía que los continentes se trasladaran por su superficie ${ }^{11}$.

Los puentecontinentistas señalaron la objeción de Jeffreys como el principal argumento en contra de la deriva ${ }^{12}$. Wegener pensaba que su teoría era

10 FRANKEL, H. (1979), «The career of continental drift theory: an application of Imre Lakatos analysis of scientific growth to the rise of drift theory», Stud. Hist. Phil. Sci., 10, pp. 21-66.

11 Hallam, A. (1989), Great geological controversies, Oxford, University Press.

12 FrAnKel, H. (1985), «The biogeographical aspect of the debate over continental drift», Earth Sci. Hist. 4(2), pp. 160-181. 
geofísicamente superior a la alternativa de los puentecontinentistas. Sin embargo, la deriva encaraba una pesada objeción geofísica. Jeffreys levantó su objeción de mayor importancia en su trabajo The Earth y continuó presentándola aun después de la aceptación de la tectónica de placas. Esta objeción levantó una dificultad conceptual a la teoría de la deriva y se convirtió en un argumento fundamental de los antiderivistas ${ }^{13}$.

De acuerdo con Wegener, los continentes habían arado su camino a través del fondo oceánico, cuando derivaron a las posiciones que tienen en la actualidad. Sin embargo, Jeffreys afirmaba que no existen fuerzas conocidas suficientes para empujar a los continentes a través del piso oceánico, y que, aun existiendo, los continentes no podrían sobrevivirían a tal viaje por la Tierra sin desmoronarse completamente, ya que el material del fondo oceánico es más fuerte que el material continental. Jeffreys se opuso a la teoría de Wegener desde el principio. En 1923 envió una carta a Nature estableciendo sus objeciones, que se mantendrían a través de sus escritos durante las siguientes cinco décadas. Jeffreys decía que en las discusiones de la teoría de Wegener, y otras hipótesis geológicas, se había supuesto libremente que cualquier fuerza, por pequeña que fuera, puede deformar la Tierra en cualquier extensión solo con que actúe el tiempo suficiente ${ }^{14}$. Criticaba el mecanismo de Wegener, consistente en una fuerza muy pequeña moviendo los continentes americanos hacia el oeste y abriendo el Atlántico detrás de ellos, mientras que la resistencia del fondo oceánico del Pacífico causaba el levantamiento de las montañas rocosas, contra la fuerza de gravedad. Jeffreys indicó que la existencia de cordilleras montañosas de millones de años de antigüedad, demuestra que las rocas en su base pueden soportar por mucho tiempo y, a gran escala, grandes diferencias de fuerza.

La objeción geofísica de Jeffreys sobre el mecanismo de desplazamiento propuesto por Wegener, fue uno de los obstáculos más importantes para el desarrollo de la teoría de la deriva continental. Sin embargo, un punto que resulta inesperado y que merece investigarse es que, finalmente, llegó a aceptarse el desplazamiento de las placas a pesar de que la tectónica de placas no ha resuelto claramente el mecanismo que lo provoca.

13 Frankel, H. (1981), «The paleobiogeographical debate over the problem of disjunctively distributed life forms», Stud. Hist. Phil. Sci, 12(3), pp. 211-259.

14 MARvin, U.B. (1974), Continental drift: The evolution of a concept USA, Smithsonian Institution Press. 


\section{EL PROGRAMA DE INVESTIGACIÓN PERMANENTISTA}

La teoría de la isostasia no solo se contrapone a la teoría de la contracción, sino también a la forma en que la teoría de los puentes intercontinentales explica la distribución orgánica. De aquí deriva, lógicamente, la teoría de la permanencia, difundida especialmente entre los geólogos americanos. B. Willis la formula de la siguiente manera: las grandes cuencas marinas son rasgos permanentes de la superficie terrestre, que desde que el agua formó mares se instalaron en el mismo lugar que actualmente ocupan. De hecho, al estudiar la naturaleza somera de los sedimentos depositados sobre los continentes, los bloques continentales son, como tales, rasgos permanentes en la historia de la Tierra. La imposibilidad de interpretar las cuencas marinas actuales como puentes continentales hundidos, debido a la aceptación de la isostasia, da como resultado una permanencia general de las cuencas marinas y de los continentes. De esta manera, la formulación de la teoría de la permanencia debida a Willis, aparece como una conclusión lógica de los conocimientos geofísicos, olvidando el postulado sobre antiguas conexiones continentales.

Wegener escribió: «...asistimos al singular espectáculo de que se defienden simultáneamente dos teorías completamente opuestas sobre la antigua configuración de la Tierra: en Europa existe una adhesión casi universal a la teoría de los antiguos puentes continentales, y en América se defiende casi exclusivamente la teoría de la permanencia de los continentes y las cuencas marinas profundas». En América la geología comenzó relativamente tarde y se desarrolló paralelamente a la geofísica, lo cual tuvo como consecuencia que los resultados de esta ciencia hermana se aceptaran más completa y rápidamente que en Europa, no existiendo ninguna tentación de convertir la teoría contraccionista en uno de los postulados básicos. Muy diferente era la situación en Europa, donde antes de que la geofísica hubiera ofrecido sus primeros resultados, la geología se había desarrollado ya durante largo tiempo, alcanzando una síntesis general concretada en la teoría de la contracción. Es por ello comprensible que para muchos geólogos europeos resultara difícil liberarse de su tradición geológica, y que por ello recibieran los resultados provenientes de la geofísica con una desconfianza que nunca llegó a desaparecer. Wegener se preguntaba: «...¿Cuál es la verdad? La Tierra no puede tener más de un rostro a la vez. ¿Hubo puentes continentales, o bien estuvieron siempre los continentes separados por mares profundos? Es imposible rechazar la reivindicación sobre las antiguas conexiones terrestres si no queremos renunciar por completo a comprender el desarrollo de la vida en la Tierra. Pero es igualmente imposible rehuir los argumentos con los que los partidarios de la 
teoría de la permanencia rechazan los intercontinentes hundidos. De lo anterior, queda solo una posibilidad: tiene que existir un error oculto en las suposiciones tomadas como evidentes». Para Wegener, éste es el punto de partida de la teoría de la deriva continental: la suposición, evidente tanto para la teoría de los puentes continentales como para la de la permanencia, de que la situación relativa de los bloques continentales no ha cambiado, es falsa. Es decir, que los continentes deben haberse movido ${ }^{15}$.

Wegener se preguntaba por qué si los movimientos verticales de las masas continentales son posibles, no podía pensarse también en la posibilidad de desplazamientos horizontales. Wegener asume que el material que forma el piso de los océanos se extiende bajo los continentes, iguala este material con el sima de Suess y lo identifica con el basalto. Da el nombre de sial al material granítico, y gneis al que compone a las formas continentales. Considerar el sial como una capa discontinua, que limita masas continentales, resultó un cambio perceptible a la interpretación de Suess de una capa continua, e hizo posible para los continentes el movimiento horizontal, similar al de una balsa. La teoría de Wegener era la más acorde con el conocimiento vigente, y desplazaba a la síntesis que había hecho Suess a fines del siglo anterior ${ }^{16}$.

Algunos geólogos americanos conservadores creyeron en la permanencia de los rasgos de la Tierra. Willis fue el principal exponente de los permanentistas, y censuró al contraccionismo en sus principios. Cuando se familiarizó con los datos de la radioactividad, cuestionó la idea que la Tierra se había estado enfriando a través de su historia. Willis se dio cuenta de que ya no se podía apelar a los puentes de tierra hundidos, e invocó una hipótesis adicional para explicar los datos paleontológicos. El punto débil de la teoría permanentista era que no daba una explicación coherente acerca del registro fósil. Willis propuso, originalmente, un hundimiento periódico de mares poco profundos, lo cual ocurrió cuando la cuenca oceánica llegó a llenarse con sedimentos erosionados de los continentes. Mientras los mares fueron someros, pudo ocurrir una proliferación de las formas de vida, que podían migrar a través de mares superficiales ${ }^{17}$.

Willis intentó aumentar el poder explicativo del permanentismo para los aspectos biológicos y paleontológicos mediante las conexiones ístmicas. En 1926 propuso una conexión ístmica como ruta migratoria de las formas de vida, las cuales se habían extendido a continentes separados por océanos.

15 Wegener, A. (1929), pp. 16-17.

16 GoHaU, G. (1990), pp. 187-200.

17 FRANKEL, H. (1979). 
Willis expresó: «Sugiero que se puede encontrar una conexión ístmica entre América del Norte y América del Sur. Se conoce que esos dos continentes han estado largamente separados y solo recientemente, geológicamente hablando, se han unido. La unión es resultado de la elevación orogénica de la cordillera entre el Caribe y el Pacífico profundo, favorecida por acumulación volcánica. El Istmo, ahora, forma un puente de tierra a través de un estrecho ecuatorial que constituye parte del mar de Tethys, y que en épocas geológicas anteriores permitió el paso de corrientes oceánicas. Homólogamente, la cordillera que ahora transporta el istmo puede ser trazada a través del Atlántico y debajo de otros océanos del hemisferio sur, y puede transportar cadenas de islas o continuas conexiones ístmicas, que expliquen la distribución pasada de los organismos» ${ }^{18}$. Esta hipótesis fue una ayuda al permanentismo, pero es cuestionable. Incluso Charles Schuchert, un paleontólogo permanentista, no quedó completamente satisfecho con la hipótesis de Willis, pues sugirió la necesidad de unos cuantos puentes de tierra hundidos como adición a las conexiones ístmicas.

Los programas contraccionista y permanentista tenían diferencias de opinión en cuanto a cuáles eran los datos más importantes que necesitaban explicación. Los contraccionistas pensaban que los datos biológicos y paleontológicos eran los más importantes, y así postularon puentes de tierra tantas veces como lo requiriera el registro fósil. Los permanentistas, por su parte, consideraban que los datos geofísicos eran los más importantes; argumentaron contra la existencia de puentes de tierra y en favor de la permanencia de los continentes y del suelo marino. Wegener pensaba que los contraccionistas ponían énfasis en lo paleontológico y los permanentistas en lo geofísico. En general, los permanentistas fueron estadounidenses y los contraccionista, europeos.

Willis señalaba que las grandes cuencas oceánicas son rasgos permanentes de la superficie de la Tierra, y han existido donde están ahora con cambios moderados de la línea de la costa. Una idea similar fue propuesta por J. Dana (1813-1895). Dana publicó en Nature una recapitulación de sus razones para sugerir, desde 1846, que «los continentes siempre han sido continentes...y nunca han cambiado su sitio con los océanos». En una serie de artículos publicados en 1873, desarrolló una teoría sobre la formación de las montañas y el origen de los continentes y los océanos, donde discutía los problemas de la subsidencia, levantamiento, deformación y metamorfismo como aspectos

18 WiLlis, B. (1928), «Continental drift», en Theory of continental drift: A symposium on the origin and movement of land masses both inter-continental and intra-continental, as proposed by Alfred Wegener, Tulsa, Oklahoma, The American Association of Petroleum Geologists, pp. 76-82. 
esenciales de la orogenia ${ }^{19}$. Dana propuso un modelo basado en la idea de una Tierra que se va contrayendo, la cual, inicialmente, estaba en estado de fusión y actualmente está en proceso de enfriamiento y solidificación. Dana proponía que, en el momento inicial de la solidificación de la superficie, había grandes áreas de composición granítica, mientras que otras estaban compuestas de corteza basáltica. La corteza, por lo tanto, debía acomodarse a esta contracción, lo que determinaba el desarrollo de fuerzas compresivas laterales dentro de la zona cortical. Debido a la diferencia de nivel entre las depresiones y altiplanicies, la corteza basáltica de las depresiones actuaría como una palanca de la corteza granítica. Por consiguiente, la presión lateral se dirigiría desde las depresiones oceánicas hacia las mesetas continentales. En un primer momento, estas presiones habrían causado un arqueamiento o flexión general de las mesetas, produciendo amplios abombamientos encima del nivel del mar y también vastas depresiones. Así se habría iniciado la erosión y el transporte de materiales rocosos desde las áreas levantadas, y, luego, su depósito en las depresiones como sedimentos. El proceso continuaba por ajuste isostático. Esta expresión indicaba el movimiento vertical de una sección de la corteza terrestre, respondiendo a un aumento o disminución del peso, según la erosión y la sedimentación, combinado con la presión lateral continuada. A medida que los sedimentos se hundían a mayores profundidades, entraban en zonas de temperaturas más altas que los reblandecían fuertemente, o los fundían. La presión lateral podía liberarse por los intensos plegamientos y fracturas de la zona que se iba debilitando, lo que conducía a la formación de cinturones de montañas con los estratos replegados. Este es el origen del concepto de geosinclinal, por el que más se recuerda a Dana en la actualidad. Así, el modelo explicaba la formación de los continentes y de las cuencas oceánicas, y, dentro de los continentes, la diferencia entre montañas plegadas, llanuras y plataforma continental. Se aplicó con gran éxito a América del Norte, donde las cordilleras más importantes son adyacentes a los océanos Pacífico y Atlántico ${ }^{20}$.

Tanto en la hipótesis de Dana como en la de Suess, el modelo de una Tierra enfriándose y contrayéndose consideraba a los continentes y cuencas oceánicas como elementos primordiales e, implícitamente, negaba la posibilidad de desplazamientos laterales importantes de las masas continentales a través de los océanos. Puesto que estos conceptos parecían explicar con éxito una amplia gama de fenómenos geológicos, la mayoría de los geólogos los acepta-

19 Holland, T.H. (1941), «The evolution of continents: A possible reconciliation of conflicting evidence», Proceeding of the Royal Society of Edinburgh, section B, vol. LXI, pp. 149-166.

20 Hallam, A. (1989). 
ban, a pesar de reconocer que existían dificultades. Por ejemplo, el concepto de orogénesis de Dana era más difícil de aplicar en Europa y Asia que en América del Norte. No es extraño, pues, que cualquier idea a favor de que los actuales continentes podían haberse separado de una masa primordial continua, pudiera parecer absolutamente herética a las primeras generaciones de geólogos.

\section{ASOCIACIONES Y RUPTURAS ENTRE TEORÍAS RIVALES}

Cuando Wegener propuso su teoría de la deriva continental, el problema de las distribuciones geográficas disyuntas había recibido fuerte atención. En ese sentido, dos alternativas fijistas, la teoría de los puentes de continentes hundidos y el permanentismo, fueron las primeras en intentar resolver el problema. Los puentecontinentistas, liderados por Suess y otros geólogos europeos y paleontólogos, postulaban la existencia de continentes primitivos o puentes de continente masivos que se extendían a través de regiones oceánicas y proporcionaban rutas migratorias para varias formas de vida. Los permanentistas, por su parte, intentaban explicar la expansión de las floras y faunas disyuntas, sin recurrir a la postulación de conexiones primitivas de tierra; sólo se interesaban por los puentes continentales existentes, como el Estrecho de Bering y América Central, en conjunto con los cambios en el nivel del mar, que permitían una movilidad grande de las formas de vida en comparación a lo admitido por los puentecontinentistas.

A la luz de las dos alternativas fijistas, Wegener desarrolló una estrategia más integral para dar una solución a las distribuciones disyuntas. Inicialmente, se alió con los puentecontinentistas contra los permanentistas, en tanto que los primeros creían que el registro paleontológico y geológico requería la postulación de conexiones intercontinentales pasadas. Sin embargo, después rompió su alianza con los puentecontinentistas, argumentaba que su teoría de la deriva continental ofrecía una mejor solución al problema debido a la superioridad de su visión en los terrenos paleontológico y geofísico.

\section{LA ALIANZA DE WEGENER CON LOS PUENTECONTINENTISTAS}

Entre los trabajos de los puentecontinentistas, Wegener recurrió al del renombrado paleontólogo alemán T. Arldt, quién en 1917 proporcionó una sinopsis de las opiniones de veinte paleontólogos importantes concernientes a la existencia de ocho conexiones intercontinentales. Para Wegener, los resultados eran claros. El primer puente continental desapareció después del co- 
mienzo del jurásico, el segundo a principios, o mediados, del cretácico, y el tercero en la transición entre el cretácico y terciario. El puente continental restante, que conectaba América del Norte con Europa, aunque frecuentemente estaba sumergido, no desapareció hasta el cuaternario. La duración y localización de estas conexiones fijaron lo que postuló Wegener sobre el rompimiento de su Pangea. Wegener discutió dos puentes hipotéticos que conectaban la Antártida con la Patagonia y Australia. El resumen de Arldt revelaba que un gran número de paleontólogos no creían en la existencia de estos puentes, a diferencia de Wegener. Habiendo utilizado los datos y argumentos de los puentecontinentalistas para desarrollar una evidencia general de varias conexiones continentales, respaldadas por muchos puentecontinentistas y constitutivas de su propia teoría, Wegener reforzó su apelación de conexiones transatlánticas citando un número de casos específicos de la literatura de los puentecontinentistas, tomando los que le parecieron más sólidos. Entre los estudios citados por Wegener, estaban los que consignaban el porcentaje aparentemente alto de reptiles y mamíferos idénticos a ambos lados del océano Atlántico, incluido el de Arldt. También citaba los resultados de un estudio sobre la flora de Groenlandia, como indicativos de una conexión primitiva. Dirigiendo su atención al Atlántico Sur, Wegener mencionaba a los géneros Mesosaurus, Glossopteris y Manatus. Mesosaurus fue un pequeño reptil mesozoico que habitaba aguas dulces (por lo tanto incapaz de atravesar los océanos), cuyos restos han sido localizados exclusivamente en Brasil y África. Los helechos del género Glossopteris tuvieron un papel importante en el debate, pues fueron comunes en los continentes australes durante finales del paleozoico, y su descubrimiento generó una especulación muy intensa por parte de paleontólogos y paleoclimatólogos. La distribución de las vacas marinas del género Manatus se restringía exclusivamente al oeste de África y a América Central y Sur, e impresionó particularmente a Wegener porque estos organismos viven en arroyos y aguas marinas cálidas y someras, aunque son incapaces de nadar a través del océano Atlántico.

Wegener posteriormente rompió con los puentecontinentistas, pues argumentó que su teoría de la deriva daba una mejor solución a las distribuciones geográficas disyuntas. Asimismo, explicaba mejor aquellos casos donde la masa continental A tenía formas de vida que se asemejan a aquellas de la masa continental B, pero absolutamente diferentes de las de la masa continental $\mathrm{C}$, aun cuando A estuviera más cerca de $\mathrm{C}$ que de $\mathrm{B}$. Wegener explicaba que A había estado más cerca de $\mathrm{B}$ que de $\mathrm{C}$ cuando las formas de vida similares florecieron, pero que la deriva había llevado a las respectivas masas continentales en sus posiciones actuales. 
Otro argumento biológico de Wegener, en favor de su teoría, fue su aplicación a la sorprendente fauna australiana del pasado y el presente. En relación con la fauna australiana, Wegener citaba a Wallace y señalaba que éste ya había reconocido una clara clasificación de esa fauna en tres elementos de diferente antigüedad. El elemento más antiguo se encuentra, fundamentalmente, en el suroeste de Australia, y muestra una interrelación con la fauna de la India y Ceilán, en particular, pero también con las de Madagascar y Suráfrica. En esta asociación se encuentran representantes que gustan del calor, como sucede con las lombrices, que evitan los suelos helados. Esta asociación se remonta al tiempo en que Australia y la India estaban unidas. La segunda asociación faunística de Australia es muy conocida, porque a ella pertenecen una serie de mamíferos peculiares, como los marsupiales y los monotremas, que se encuentran diferenciados de las fauna de las islas de la Sonda (frontera de los mamíferos, de acuerdo con Wallace). La tercera asociación faunística, la más reciente, es la que ha emigrado de Sonda estableciéndose en Nueva Guinea, y ha comenzado a colonizar el noreste de Australia. El dingo, los roedores, los murciélagos y otros mamíferos han emigrado a Australia durante el post-plioceno.

Las tres subdivisiones de la fauna australiana concuerdan perfectamente con la teoría de los desplazamientos. Dice Wegener que precisamente estas circunstancias nos muestran de la forma más clara posible la superioridad de la teoría movilista sobre la de los puentes hundidos, incluso si nos atenemos únicamente a hechos biológicos. De hecho, la fauna australiana va a proporcionar el material más importante con el que la biología puede contribuir al problema general de los desplazamientos continentales. Partiendo de la división tripartita de los animales australianos, Wegener argumentaba que la naturaleza de cada grupo, así como sus diferencias, podrían ser explicadas solo por su teoría de la deriva. El elemento más antiguo se origina en el momento en que Australia estaba aún conectada con la India. El segundo elemento faunístico muestra una relación de parentesco con la fauna sudamericana. En cuanto al tercero, Wegener lo interpreta como indicador de un cambio rápido de la fauna y flora, el cual comenzó en un tiempo geológico reciente.

La otra objeción de Wegener a la teoría de los puentes continentales era geofísica más que biológica. La consideró una objeción muy seria, y en ello estuvo de acuerdo con los permanentistas. Consistía en que la doctrina de los puentes continentales hundidos era incompatible con el principio de la isostasia. Si se aceptaba este principio, los puentecontinentistas no tenían un modo razonable para hundir los puentes continentales que postulaban dentro del fondo oceánico, a menos que ocurriera un proceso de sobrecarga que incrementara la densidad de los puentes lo suficiente para que se hundieran. Sin 
embargo, no se tenía conocimiento de ningún proceso que aumentara su densidad. Por ello, no sorprende que Wegener adujera que su teoría ofrecía una mejor solución a las distribuciones geográficas disyuntas, comparada con las hipótesis permanentista y de los puentes continentales. Aunque los puentecontinentistas ofrecían una explicación a la distribución biológica, tanto actual como pasada, contradecía el principio de isostasia. Wegener criticaba también a los permanentistas, que eran incapaces de explicar el registro paleontológico, en el que había abundantes casos de formas terrestres similares separadas por vastos océanos. En su opinión, los permanentistas no daban realmente una solución satisfactoria a las distribuciones geográficas disyuntas.

Desde luego, hubo respuestas de los puentecontinentistas. Hubo ataques abiertos a la solución que proponía Wegener, y se señalaron contraejemplos. En 1923 se llevó a cabo un simposio, sostenido por la Real Sociedad de Suráfrica, sobre la distribución de formas de vida en el hemisferio sur y su relación con la hipótesis de Wegener a las distribuciones geográficas disyuntas. Hubo objeciones a la teoría wegeneriana, como la del botánico Compton, que consideraba a la evidencia de la distribución vegetal como totalmente opuesta a la teoría de Wegener; o la del entomólogo Perigwag, el cual consideraba que la teoría de los puentes continentales explicaba más fácilmente la distribución de los insectos. Otra acusación general fue la de E. W. Berry, un eminente paleontólogo americano. En el primer encuentro internacional sobre la teoría de la deriva, auspiciado en 1926 por la Asociación Americana de Geólogos Petroleros (AAGP), Berry formuló que la teoría de Wegener, desde el punto de vista paleontológico, provocaba más problemas que los que resolvía. El paleobotánico europeo L. Diels presentó varias objeciones a la solución dada porWegener a las distribuciones disyuntas, argumentando que era incompatible con los datos de la paleobotánica, ya que la flora del este de América del Norte estaba ligada con la flora del este de Asia más que con la de Europa. La flora vestigial de Europa no era parecida a la de América del Norte, pero estaba relacionada con la flora asiática y la flora autóctona de Australia; era tropical más que de climas fríos como debiera esperarse de acuerdo a la teoría de Wegener.

Otras objeciones vinieron de tres paleontólogos altamente respetados, quienes estaban entre los defensores más vehementes de la hipótesis de los puentes continentales: J. W. Gregory, C. Schuchert, y H. von Ihering. Gregory, un líder entre los paleontólogos británicos que defendían la hipótesis de los puentes continentales, estableció una objeción general para la solución dada por Wegener a las distribuciones geográficas disyuntas. Objetó que Wegener era incapaz de explicar las similitudes biológicas a ambos lados del Pacífico. Él pensaba que estas similitudes eran tan forzadas como las encontradas en las líneas coste- 
ras del Atlántico. Argumentaba a favor de los puentes continentales y postulaba puentes de conexión a través del Pacífico. Shuchert, paleontólogo americano que surgió de una tradición europea puentecontinentista, argumentó a favor de esta escuela en el simposio de 1926 de la AAGP, donde hizo varias objeciones a la solución de Wegener. En particular, él estaba de acuerdo con la objeción de que la teoría de Wegener rompía la conexión entre el este de Rusia y Alaska. Schuchert optó por la teoría de los puentes continentales, pues pensaba que ésta podría explicar la dispersión de formas de vida lejanas con mayor facilidad que la hipotética pangea de Wegener. Von Ihering expresó su absoluto menosprecio por la teoría de Wegener, afirmando que unir las líneas de la costa de África y América del Sur era una idea ingenua, y que entraba en directa oposición a todos los hechos probados por los estudios geológicos y la distribución geográfica de los animales. Consideró además que la teoría de los puentes continentales era superior a la hipótesis de la deriva, con base en que los bordes del Pacífico eran necesarios y que el Atlántico sur requería conexiones continentales intermitentes.

La respuesta crítica de los puentecontinentistas se puede sintetizar en tres puntos: (1) que las notables similitudes entre formas de distribución disyunta se explicaban mejor y más económicamente por la teoría puentecontinentista que por la teoría de la deriva continental; (2) que la deriva hacía extremadamente difícil explicar muchas formas disyuntamente distribuidas, especialmente las transpacíficas; (3) que en el caso específico de la distribución de Glossopteris, su hallazgo en Rusia se explicaba más fácilmente dejando a los continentes en sus posiciones actuales que recurriendo a la reconstrucción de la pangea wegeneriana ${ }^{21}$.

\section{EL PERMANENTISMO REDIVIVO}

El permanentismo también desarrolló soluciones a las distribuciones geográficas disyuntas. Schuchert ${ }^{22}$ y Willis ${ }^{23}$ presentaron una alternativa. Schuchert resumió los datos paleontológicos y modificó su posición, de un puentecontinentista que requería conexiones intercontinentales sustanciales pasó a

21 FrANKEL, H. (1985), «The biogeographical aspect of the debate over continental drift», Earth Sci. Hist, 4(2),, pp. 160-181.

22 Schuchert, Ch. (1932), «Gondwana land bridges», Bull. Geol. Soc. Amer, 43, pp. 875-915.

23 Willis, B. (1932), «Isthmian links». Bull. Geol. Soc. Amer, 43, pp. 917-952. 
ser un permanentista generoso que requería solo enlaces ístmicos entre los continentes. Willis, un líder entre los geólogos americanos y un fuerte opositor a las teorías de la deriva y de los puentes continentales hundidos, proporcionó a Schuchert suficientes puentes continentales en la forma de conexiones ístmicas para explicar los datos paleontológicos. A diferencia de los puentes continentales, las conexiones ístmicas no estaban sujetas a la objeción geofísica concerniente al principio de la isostasia.

La más completa y vehemente defensa paleontológica del permanentismo fue de G. G. Simpson (1902-1984), uno de los paleontólogos más influyentes en América, quien extendió, en gran medida, el trabajo de otro eminente paleontólogo americano, W. D. Matthew, y desarrolló una solución permanentista sofisticada a las distribuciones geográficas disyuntas. Además, Simpson lanzó un fuerte ataque contra los defensores de la deriva continental y los puentecontinentalistas. En su momento, A. du Toit contestó defendiendo la deriva, y C. Longwell continuó el debate. Simpson desarrolló su solución para explicar la distribución disyunta de los mamíferos, y delineó tres tipos de rutas de dispersión. La primera, a la que denomina corredores o pasillos, son conexiones de tierra que permiten el paso de los animales en ambas direcciones. La segunda, llamada puentes filtro, combina una conexión terrestre con algún factor adicional, como el clima, de forma que elimina algunos posibles migradores. Por ejemplo, parece improbable que los animales de climas cálidos cruzaran el estrecho de Bering cuando estaba emergido entre Asia y América del Norte durante el Pleistoceno; el pasaje estaba abierto únicamente cuando el nivel del mar descendía en las épocas más frías de las glaciaciones. La tercera categoría, las rutas sweepstake, toma su nombre de la pequeña proporción de vencedores respecto al gran número de perdedores; los raros vencedores son aquellos que sobreviven a los viajes fortuitos y tienen éxito al colonizar áreas aisladas. A diferencia de los pasillos o los puentes filtro, que favorecen la homogeneidad final de las faunas a ambos lados del corredor, las rutas sweepstake impulsan el establecimiento de poblaciones de baja diversidad y ecológicamente desequilibradas ${ }^{24}$. Las tres rutas que define Simpson son las disponibles para los animales terrestres en general y, especialmente, para los vertebrados superiores. Sin embargo, el mismo tipo de conexiones debería influir también sobre la dispersión de organismos marinos, como los invertebrados que habitan los fondos marinos. Simpson dice: «La opinión más radicalmente sostenida que todavía defienden algunos investigadores competentes implica la teoría del desplazamiento de continentes. Hay varias

24 Hallam, A. (1972),pp. 81-90. 
versiones contradictorias de esta teoría, pero todas suponen que los bloques continentales primeramente tenían relaciones y posiciones completamente distintas sobre el esferoide terrestre(...). Los geólogos están muy lejos de coincidir, no solo en los detalles del proceso, sino incluso en si realmente se produjo. La mayoría de los geólogos americanos creen que no. Los geólogos europeos están más divididos en la opinión. La mayoría se inclina a aceptar la probabilidad del desplazamiento de los continentes. Los geólogos sudafricanos son particularmente adictos a la teoría, en gran parte por la influencia personal de un expositor capaz e inspirado, A. du Toit, que trabajó y enseñó en Suráfrica». Sin embargo, Simpson sentenciaba: «creo que puede decirse que lo que se sabe en realidad de la geografía actual y pasada de los animales y plantas no apoya la teoría del desplazamiento de los continentes» ${ }^{25}$. Simpson desdeñó mucha de la literatura relacionada con las distribuciones geográficas disyuntas, y fue poco clemente en su trato crítico con Wegener y Toit. A lo largo de su ataque, se concentró en mostrar que sus oponentes habían sobrestimado toscamente el número de casos legítimos de organismos disyuntamente distribuidos, mediante la utilización de datos inexactos, basados en criterios taxonómicos inadecuados o en identificaciones erróneas de especímenes fósiles. Junto con el descrédito de sus competidores, su ataque tuvo el efecto de disminuir considerablemente el número de casos legítimos de formas disyuntamente distribuidas.

Pero, ¿cuál fue la respuesta de Toit al ataque de Simpson? Simplemente dio un paso atrás. Aceptó que se había sobrestimado la importancia de la deriva continental como solución para las distribuciones geográficas disyuntas en la evaluación general de la teoría. Sin embargo, enfatizó que este paso atrás se debió, como el mismo Simpson aceptaba, a que la base de datos biogeográficos era incompleta e informal. Toit también intentó hacer a un lado el trabajo de Simpson, argumentando que la distribución de los mamíferos realmente se modeló poco después de que muchos movimientos laterales de la deriva hubieran ocurrido, y que sus patrones eran muy diferentes a los mostrados por los invertebrados y las plantas.

La defensa de Simpson del permanentismo influyó fuertemente entre los zoogeógrafos norteamericanos. Casi sin excepción, se adhirieron a esta postura y argumentaron contra la deriva como solución a las distribuciones geográficas disyuntas. A. Romer fue el más prominente de los pocos zoólogos norteamericanos de vertebrados que mostraron simpatía por la hipótesis de la deriva continental antes del surgimiento del paleomagnetismo, entre la década de los años

25 Simpson, G.G. (1967), La vida en el pasado: Una introducción a la paleontología, Madrid, Alianza Editorial, pp. 103-124. 
40 y 50. Romer, un especialista en tetrápodos, comparó los reptiles del Pérmico y los anfibios de depósitos en Texas y Checoslovaquia, y encontró que la fauna era extremadamente similar, mostrando que el grado de similitud fue mayor durante el Pérmico que en la actualidad. Sin embargo, señala Frankel, Romer expresó su conclusión con cautela y fue renuente a elegir entre las hipótesis de los puentes de tierra entre continentes y de la deriva continental.

Los especialistas americanos en zoología de invertebrados y fitogeografía, también siguieron las enseñanzas de Simpson. El líder americano en entomología, P. J. Darlington Jr., defendió la solución permanentista para las distribuciones geográficas disyuntas. A finales de los cuarenta, y durante los cincuenta, Darlington tuvo poca simpatía por la teoría de la deriva, aunque, al menos, estaba dispuesto a considerarla. Entre los fitogeógrafos, D. Axelrod, R. Chaney, y W. Darrah se mantuvieron como líderes permanentistas de entre todos los que han pugnado contra la solución de la deriva. Axelrod, por ejemplo, no la aceptó hasta que poco después la comunidad de las ciencias de la Tierra la estableció formalmente mediante la tectónica de placas. El consenso general de la comunidad científica americana en favor del permanentismo fue expuesto durante el simposio de 1949, The problem of land connections across the South Atlantic, with special reference to the Mesozoic, celebrado en Nueva York por la Sociedad para el Estudio de la Evolución. De los 17 participantes, solo tres mostraron apoyo a la teoría de la deriva continental. Ellos eran Romer, W. Camp y el fitogeógrafo K. E. Castor. Romer, en el simposio, citó a Mesosaurus como la más fuerte evidencia para las conexiones transatlánticas suramericanas, ya que sus restos habían sido encontrados solo en Sudáfrica y América del Sur, y nadie podría afirmar que esta especie fue capaz de cruzar el océano Atlántico Sur.

Frankel ${ }^{26}$ ha presentado argumentos, aparentemente, persuasivos y detallados a favor de la tesis según la cual el debate sobre las distribuciones biogeográficas disyuntas, tanto antiguas como actuales, quedó resuelto por los avances en oceanografía y paleomagnetismo. La tesis central, que sostiene es que la biogeografía, que posee una base de datos inadecuada, debe fundarse en otra ciencia, la geología, que tiene un mejor sustento de información. De acuerdo con $\mathrm{Craw}^{27}$, el capítulo de Wegener «Argumentos paleontológicos y biológicos», propone hipótesis biogeográficas falsables, aunque éstas fueron ignoradas por los críticos inductivistas y permanentistas, principalmente Simpson. La

26 FRANKEL, H. (1981).

27 CRAW, R.C. (1984), «Conservative prejudice' in the debate over disjunctively distributed life forms», Stud. Hist. Phil. Sci., 15(2), pp. 131-140. 
crítica esencialmente inductivista de Simpson involucra supuestos ad hoc respecto a la dispersión. Incluso, es de notar que Simpson, cuyos puntos de vista eran muy diferentes a los de Léon Croizat, rehusó siquiera considerarlos dedicándose únicamente a desacreditarlos. Craw señala que, comparando solo una parte del capítulo VI de Wegener con trabajos biogeográficos posteriores, como los de Brundin ${ }^{28}$ y Rosen ${ }^{29}$, se aprecia la amplia corroboración de las predicciones de Wegener. El enfoque inductivista de Simpson revela, claramente, su creencia de que la ciencia avanza mediante la lenta acumulación de hechos más que por la producción de conjeturas audaces, es decir en un modelo ad hoc para la adquisición del conocimiento, que implica verificación y certeza de conocimiento, más que falsabilidad. Señala Simpson «toda la evidencia crucial a favor de la tectónica de placas se adquirió después del trabajo de Wegener, Du Toit, y otros proponentes tempranos de la deriva continental. Fue esto y no la hipótesis y los argumentos de los pioneros lo que hizo al principio plausible la deriva continental y al final, virtualmente incontrovertible» ${ }^{30}$.

\section{LA RESPUESTA DE LOS DERIVISTAS}

No todo estaba oscuro para la solución de Wegener al problema de las distribuciones disyuntas. Mucho apoyo provino de Toit y los paleobiogeógrafos, especialmente aquellos especializados en fitogeografía. Wegener ofreció apoyo adicional a las distribuciones geográficas disyuntas en las últimas ediciones de su obra. En su último trabajo, Wegener tocó los aspectos fitogeográficos de las distribuciones geográficas disyuntas, uniéndolos con los paleoclimáticos. Debido a que las plantas están más sujetas a factores climáticos que los animales, este trabajo tuvo más efecto en la comunidad paleofitogeográfica en comparación con la zoológica, donde no tuvo mucha repercusión. A. du Toit, en cambio, atribuyó más peso a la solución de la deriva que cualquier otro defensor de la teoría de Wegener. Sin embargo, su énfasis sobre la solución de la deriva a las distribuciones geográficas disyuntas entró lentamente, pues él, al inicio, no atribuyó mucha importancia a este punto, hasta 1937, cuando publicó Our wandering continents.

28 BRUNDIN, L. (1966), «Transantartic relationships and their significance as evidenced by chironimid midges», Svenska Vtenskapsakad Handl, 11, pp. 1-472.

29 ROSEN, D.E. (1978), «Vicarience pattern and historical explanation in biogeography», Syst. Zool., 27, pp. 159-188.

30 Simpson, G.G. (1976), «The Compleat Paleontologist?», A. Rev. Earth Plan. Sci., 4 pp. 1-13. 
El mayor apoyo a las ideas de Wegener provino de los fitogeógrafos. Entre los zoogeógrafos, parece que los especialistas en invertebrados apoyaban más la deriva continental para explicar las distribuciones disyuntas que sus colegas especializados en vertebrados. Ciertamente, el caso de los ataques más fuertes contra la solución de la deriva vino de los paleontólogos de vertebrados. Otros de los que ofrecían apoyo a la solución de la deriva lo hacían moderadamente, con observaciones preventivas, en donde mencionaban herrores en los datos, soluciones alternativas o la pesada objeción geofísica que la deriva tenía que encarar.

El principal fitogeógrafo que optó por la solución de la deriva para las distribuciones geográficas disyuntas fue el paleobotánico británico, A. C. Seward. En un escrito de 1929, dirigido a la sección de botánica de la Asociación Británica para el Avance de la Ciencia, Seward reafirmó su simpatía por la solución de la deriva, aunque admitió que existían serias objeciones a la hipótesis de Wegener. Sin embargo, la consideraba como una hipótesis que merecía ser probada y defendida. Los extensos depósitos glaciares del permocarbonífero habían sido descubiertos en todos los continentes del sur, incluida la India, y estaban asociados con Glossopteris. Wegener y los otros derivistas pensaban que la solución de la deriva a esos depósitos glaciares era una buena razón para aceptarla, resolviendo el problema al reunir los continentes del sur y la India alrededor del polo sur. Seward, como muchos paleobotánicos, creía que las plantas son mucho mejores indicadores de la temperatura de los climas pasados que los animales. Argumentaba que la localización de la flora en el permocarbonífero requería climas completamente diferentes a los actuales, y utilizó esta tesis, junto con la distribución de Glossopteris, como un apoyo a la deriva. Seward también tuvo influyó en disyuntas en algunos de sus estudiantes, como J. Walton, B. Sahni y R. Good. Sahni, quien más tarde se convirtió en el paleobotánico más respetado, miembro de la Royal Society, defendió la solución de la deriva hasta su muerte, en 1949. A mediados de los treinta presentó un nuevo argumento a favor de la deriva basado en la proximidad de la flora de Glossopteris con la flora Cathaysiana (Gangamopteris) de China. Argumentaba que la India debió haberse movido hacia el norte como lo sugirieron Wegener y Toit. Good fue otro de los estudiantes que defendió enérgicamente el argumento fitogeográfico. Comenzó apoyando la deriva a finales de los treinta, con su trabajo Geography of flowering plants, y continuó defendiéndola a lo largo de la aceptación de la tectónica de placas a finales de los sesenta en ediciones subsecuentes de su libro.

Hoeg, un paleobotánico europeo, no deseaba apoyar a la teoría de la deriva, pero estaba impresionado por su solución a la distribución de Glossopte- 
ris. Tuvo oportunidad de examinar algunos de los hallazgos de Glossopteris en Rusia, en 1932, y concluyó que en realidad no eran de Glossopteris sino que habían sido incorrectamente determinados. Un apoyo adicional provino de dos paleobotánicos americanos. Uno de ellos, D. Campbell, de la Universidad de Stanford, sostenía en 1944 que la teoría de la deriva continental era la única explicación plausible de la presente distribución de las plantas.

De acuerdo con Frankel ${ }^{31}$, aunque el respaldo de la zoogeografía no fue tan grande como el de la fitogeografía, hubo no obstante algunos zoogeógrafos europeos que apoyaban la teoría de la deriva continental, incluidos unos pocos británicos, pero difícilmente había algún norteamericano que respaldara esa teoría. En general, era más frecuente que los europeos apoyaran la hipótesis de los puentes continentales, mientras que los americanos, casi sin excepción, favorecían la alternativa permanentista. Un europeo que apoyó decididamente a la deriva, desde los terrenos de la zoogeografía, fue L. Joleaud. Este eminente paleontólogo francés, que en un principio creía en la teoría de los puentes continentales, cambió su postura para respaldar la teoría de la deriva continental en los primeros años de los veinte, y continuó defendiéndola hasta su último trabajo. Joleaud, independientemente de los postulados de Wegener y Toit, desarrolló un modelo sobre el movimiento de los continentes semejante a un acordeón, que permitía las aperturas y cierres del océano Atlántico. Apeló a la distribución de vertebrados e invertebrados para argumentar su defensa de la deriva como solución a las distribuciones geográficas disyuntas.

La recepción de la deriva por parte de los científicos australianos y neozelandeses fue predominantemente negativa. Derivistas como S. W. Carey, L. Harrison, A. Wade, J. W. Evans y W. D. L Ride, estaban en minoría, mientras que los mayores científicos australianos, como T. W. Edgeworth David, W. R. Browne, E. C. Andrews, W. H. Bryan, E. R. Hills, A. H. Voisey y C. Teichert, eran permanentistas. Sin embargo, debe señalarse que gran parte del trabajo respaldado por la Universidad Nacional Australiana en los cincuenta y sesenta, contribuyó enormemente a la evidencia paleomagnética en favor de la deriva continental (Frankel, 1984). Australianos y neozelandeses comenzaron a respaldar la deriva poco después de que tuvieron conocimiento de estos estudios paleomagnéticos. Entre los derivistas australianos se destaca S. W. Carey, quien se inclinó hacia la hipótesis de la expansión de la Tierra antes de que la tectónica de placas se convirtiera en la teoría dominante.

En la negativa a aceptar la teoría de la deriva hubo un elemento racional importante. Esto es, no existían evidencias que apoyaran suficientemente la

31 FRANKEL, H. (1979). 
teoría del desplazamiento continental. Un amplio sector de la comunidad geológica se mantuvo escéptico ante esta propuesta, en tanto no hubo evidencia empírica de la expansión del fondo oceánico y la tectónica de placas. Sin embargo, en general, la teoría de la deriva, tuvo una recepción más bien hostil en América del Norte, Australia y Nueva Zelanda, fue recibida favorablemente en Sudáfrica y la India, y recibió una aceptación mixta en Europa y América del $\operatorname{Sur}^{32}$. Frankel sugiere que el factor más importante que influyó en esta diferencial aceptación en diferentes regiones, fue la habilidad relativa de la deriva y el permanentismo para explicar la geología de cada región en particular. Si la deriva podía resolver problemas regionales importantes de una mejor manera que el permanentismo, ésta recibía una aceptación más favorable. Si ambas teorías eran más o menos eficientes para resolver el mismo número de problemas regionales de importancia, entonces los méritos relativos de cada solución y la importancia de los problemas respectivos eran significativos, aunque en tales casos la recepción era más balanceada. En síntesis, la teoría favorecida dependía de la geología de la región.

\section{CONCLUSIONES}

Según Lakatos ${ }^{33}$, un nuevo programa de investigación debe sustituir a otro ya establecido sí: (1) explica también todo lo interpretado por éstos; (2) predice hechos nuevos; (3) algunos de los hechos nuevos son confirmados. El programa de la deriva continental sustituyó al contraccionismo y al permanentismo hacia mediados de la década de 1960. Si aplicamos la metodología de Lakatos al desarrollo de la teoría de la deriva continental, la versión del desplazamiento de Wegener - incluso cuando se combinó con la hipótesis de Holmes y Toit-, debería satisfacer todas las condiciones. Sin embargo, para Frankel esta metodología falla, ya que no satisface la última de las condiciones puesto que estrictamente hablando, las hipótesis auxiliares derivistas no predijeron hechos nuevos para ser corroborados ${ }^{34}$.

Wegener, ciertamente, pensó que el desplazamiento explicaba más datos paleontológicos y geofísicos que cualquiera de los programas de investigación establecidos. Desde luego, la gran virtud de la teoría de la deriva fue su

32 Frankel, H. (1984), «Biogeography, before and after the rise of sea floor spreading», Stud. Hist. Phil. Sci., 15(2), pp. 141-168.

33 LAKATOS, I. (1983), La metodología de los programas de investigación, Madrid, Alianza.

34 FRANKEL, H. (1979). 
gran capacidad de síntesis. Wegener recurrió a la información que provenía de la geología, geofísica, paleontología y paleoclimatología. Es así, que la teoría de Wegener llegó a explicar más datos que la versión de Suess del contraccionismo y la teoría original de Willis del permanentismo. Sin embargo, es dudoso que explicara todos los datos que explican las versiones del contraccionismo de Chamberlin y Jeffreys, aunque ambas se apoyan en los datos geofísicos de sus programas. Sin embargo, el desplazamiento de Wegener predice hechos nuevos. El más obvio concierne a la deriva de los continentes. Puesto que Wegener mantuvo que el desplazamiento hacia el oeste de las Américas y Groenlandia todavía estaba sucediendo, o que al menos no había razón teórica para suponer que se había detenido, sugería que debía intentarse medir tal desplazamiento. Así, la versión de Wegener sobre el desplazamiento satisface las dos primeras condiciones del modelo de Lakatos.

El punto es entonces, ¿se corroboró alguno de los hechos predichos por el desplazamiento de Wegener? En retrospectiva sabemos que no fue así, aunque Wegener pensó que al menos uno sí había sido corroborado por el Danish Institute. En 1922 el Instituto reportó un desplazamiento observado de Groenlandia. Se compararon las mediciones geodésicas antiguas con los registros del propio Wegener. La diferencia indicaba un cambio hacia el oeste de Groenlandia, si bien el desplazamiento resultó ser más rápido que lo que Wegener esperaba. Sin embargo, la medición del desplazamiento de Groenlandia no se estableció hasta 1936, y no se reportó claramente hasta 1944 por Longwell. Consecuentemente, parecería que la geología debería haber iniciado un cambio hacia la teoría de la deriva. En los hechos, eso no ocurrió directamente, porque se cuestionaba con buenas razones la inferencia de Wegener sobre el corrimiento de Groenlandia. Wegener comparó el desplazamiento aparente de Groenlandia. Tomó los datos radiotelegrafiados de 1927 y los cotejó con los primeros datos de 1922. El Danish Institute consideró que la lectura de 1922 no era fiable, sólo la de 1927. El Instituto avaló la lectura que su personal había realizado en 1927, y se deslindó de la lectura de 1922. Desde luego, a posteriori, puede considerarse que cualquiera de las dos mediciones podían tomarse como evidencia a favor de que Groenlandia se ha desplazado. Sin embargo, en ese tiempo, el contraccionismo y el permanentismo tuvieron una buena razón para no interesarse en corroborar el nuevo hecho que proponía Wegener, debido a que la observación del 22 no era segura. No obstante el recibimiento escéptico que tuvo en su momento la predicción de Wegener, el desplazamiento de Groenlandia constituía una predicción nueva, de acuerdo con el modelo de Lakatos.

Los adherentes de los programas contraccionista y permanentista podrían considerarse como falsacionistas ingenuos. Es cierto que existían circunstan- 
cias de carácter técnico que dificultaban una estimación precisa del desplazamiento, y que, por tal razón, los integrantes de esos programas consideraron que el desplazamiento continental no había podido ser corroborado. Sin embargo, de acuerdo con Lakatos, el falsacionismo sofisticado, a diferencia del ingenuo, considera que ningún experimento, informe experimental, enunciado observacional o hipótesis falsadora corroborada de bajo nivel pueden originar por sí mismo la falsación. Para Lakatos los experimentos cruciales no existen, al menos si nos referimos a experimentos que puedan destruir instantáneamente a un programa de investigación.

Otro punto importante a debatir es la caracterización que hace Frankel del núcleo duro de la teoría derivista. Para él, consiste en que los continentes se han desplazado horizontalmente entre sí. Ciertamente, los continentes, ahora separados por vastos océanos, estuvieron una vez juntos. Frankel no señala cómo se llega a conformar este núcleo duro. Si bien la metodología de Lakatos no exige que así se haga, Frankel debió proporcionar una guía de las razones para caracterizarlo de esta manera. En esos términos, se asume que además del desplazamiento de los continentes, éstos debieron haber estado unidos en un tiempo pasado. Taylor por ejemplo, no menciona propiamente el concepto de una unión previa de los continentes y queda, por lo tanto, excluido. Además, el contexto histórico anterior al desarrollo del programa de investigación derivista no es analizado ni considerado por Frankel. Según Lakatos, algunos de los programas de investigación más importantes de la historia de la ciencia estaban insertados en programas más antiguos, con relación a los cuales eran claramente inconsistentes; por ejemplo, la astronomía copernicana dentro de la física aristotélica. Tanto Wegener como Taylor consideraban el desplazamiento horizontal de los continentes. Ello parece ser una expresión más correcta del núcleo duro del programa de investigación derivista que la ofrecida por Frankel, quien parece no haber tomado en cuenta las ideas de Snider y Taylor como evidencias a favor del desplazamiento continental para definir su núcleo duro. Al considerar solamente a Wegener, excluye a los demás.

La heurística positiva del programa de investigación derivista se establece a partir de las líneas de desarrollo aportadas por las hipótesis auxiliares que Wegener proporciona a la teoría del desplazamiento, como son las evidencias geodésicas, geofísicas, geológicas, biogeográficas y paleoclimáticas. Estas hipótesis auxiliares circundan al núcleo duro, que es el desplazamiento horizontal de los continentes, estableciéndose así un cinturón protector. Otras hipótesis auxiliares desarrolladas por el programa son las de Holmes y Toit. El desarrollo de la teoría de la deriva continental conllevó la elaboración de hipótesis auxiliares, como la de Holmes, que elaboró su teoría sobre las corrientes de convección para ex- 
plicar el mecanismo del desplazamiento, y la de Toit sobre las similitudes geológicas entre América del Sur y Sudáfrica, así como su idea de la existencia de dos supercontinentes, Laurasia y Gondwana, en vez de una única pangea.

Siguiendo el modelo de Lakatos, ¿sería posible establecer si el programa wegeneriano es un programa de investigación progresivo? Si consideramos la época en que fue propuesto el programa derivista, compitiendo con los programas contraccionista y permanentista, y considerando que la primera medición que se hizo sobre el desplazamiento de Groenlandia se consideró como dudosa, no sería posible establecer si el programa de investigación derivista era un programa progresivo con respecto a los programas rivales. Los tres programas competían en las explicaciones alternativas que daban acerca de la configuración de la Tierra, la formación de cadenas montañosas y la distribución anómala de los organismos. Los tres explicaban de manera más o menos adecuada, la formación de montañas, aunque los más sólidos eran el permanentismo y el derivismo. El contraccionista asociado a los puentecontinentalistas tenía tantos problemas que tuvo que ser relegado. El programa derivista parece explicar, con evidencias más sólidas, el caso particular de la distribución geográfica anómala de algunos grupos de organismos. Tal vez, en esa época era difícil evaluar adecuadamente esas evidencias, y fueron consideradas por algunos sectores de la comunidad como insuficientes. Pero si visualizamos las hipótesis biogeográficas de Wegener a la luz del conocimiento actual, debemos admitir que existían evidencias claras a favor de la tesis del desplazamiento. Desde luego, este es un juicio presentista. Lo adecuado sería juzgar el programa derivista en su momento. Como anteriormente se mencionó, de acuerdo con una interpretación diacrónica, el programa derivista no fue progresivo con respecto a los programas rivales.

La recepción de la teoría de la deriva continental de Alfred Wegener por parte de la comunidad científica fue heterogénea. Fue muy discutida, tanto por adherentes como detractores, en Alemania, Francia, Italia, Bélgica, Suiza, Holanda, Austria, España, India, Sudáfrica, Australia, Nueva Zelanda, Inglaterra y Estados Unidos. Hubo sectores específicos de la comunidad geológica a los cuales no les satisfizo la argumentación wegeneriana. En unos casos, como en Inglaterra y los Estados Unidos, la reacción llegó a ser hostil. En España fue bien recibida. Sin embargo, tal parece que la oposición de ciertos sectores de la comunidad geológica no fue en todo momento racional. Contrasta con ello el simposio de Nueva York, donde se llevó a cabo una discusión seria y se llegó a una conclusión que no la descalificaba totalmente. Algunos textos consultados refieren que de un total de 14 participantes, cinco eran partidarios, cuatro opinaron que valía la pena analizar y discutir el nuevo 
enfoque, cinco emitieron opiniones negativas y fueron francamente hostiles. Sin embargo, la opinión adversa fue la única que prevaleció, lo cual contribuyó fuertemente a que la comunidad geológica no aceptara la teoría de la deriva continental, relegándola al olvido hasta la posguerra.

La tesis del provincialismo podría ser una explicación adecuada para las diferencias de opinión existentes con relación a la teoría del desplazamiento continental ${ }^{35}$. El provincialismo en geología existe por muchas razones, entre otras, que los datos de la geología están literalmente ligados a la investigación de campo. Los geólogos, en su mayor parte, deben ir al campo para examinar los datos, más que hacer experimentos en el laboratorio. Por supuesto, existen fósiles y rocas recolectadas, así como mapas y fotografías. Sin embargo, el trabajo taxonómico para la revisión de los ejemplares es detallado, laborioso y se dificulta si no se comparan los fósiles con los especímenes actuales. Otro punto a considerar es que los geólogos tienen una desconfianza natural de los informes de campo de otros geólogos. Debido a que muchas de las evidencias clásicas para la deriva continental requerían establecer semejanzas geográficas, geológicas y paleontológicas entre diferentes regiones, el carácter localista del trabajo geológico tuvo un efecto negativo sobre la deriva continental. El provincialismo fue la causa de que muchos geólogos no trataran los problemas con una visión global y obstaculizó, en particular, la evidencia clásica sobre el desplazamiento continental, aunque tuvo poco efecto sobre la aceptación de la teoría de la expansión del fondo oceánico y de la tectónica de placas. La evidencia clásica dependió, principalmente, de la geología continental, donde el provincialismo era un factor significativo, mientras que la evidencia moderna para la deriva continental dependió principalmente de los avances en el paleomagnetismo y de la geología submarina, donde el provincialismo tuvo poco efecto, en particular porque los equipos de trabajo tienen una visión global de la actividad que realizan.

El estatus relativo del desplazamiento fue cuesta abajo durante los años 40, y luego hizo un descubrimiento sustancial durante la mitad de los 50, a través de los estudios del magnetismo remanente, aunque no sustituyó a los programas establecidos. Estos estudios atrajeron nuevos seguidores y despertaron interés. El primer simposio de la posguerra sobre el desplazamiento se realizó en la universidad de Tasmania, en 1956, y se inspiró particularmente en los estudios sobre magnetismo. Se publicaron varios libros que trataban el problema de la deriva polar y el desplazamiento continental. El desplazamiento no se aceptaba plenamente aún, pues no había una corroboración decisiva de este

35 Frankel, H. (1984). 
fenómeno. Dos grupos de investigación, representados por Blackett y Runcorn, consideraron que sí había una corroboración cuantitativa del desplazamiento. La India había migrado hacia el norte, colisionando con Asia; Norte y Suramérica se separaron de Europa y África, abriendo el océano Atlántico en el Eoceno. Runcorn aceptó el desplazamiento porque él mismo había corroborado la apertura del Atlántico. Sin embargo, sus estudios podían interpretarse de otra manera. La deriva polar podía, igualmente, explicarse sin implicar desplazamientos, por lo que resultó aceptable para los miembros de los programas establecidos. No requiere desplazamiento horizontal de la corteza, relativo a la corteza o de la litosfera en relación con la litosfera, solo de la corteza con respecto al manto, o de la litosfera con respecto a la astenosfera ${ }^{36}$.

Tiempo después, el desarrollo de la investigación paleomagnética, el reconocimiento de la expansión del fondo oceánico por Hess y Vine-MatthewsWilson, y la teoría de la tectónica de placas expuesta en Nature en 1967 por D. P. Mackenzie y R. L. Parker, hicieron que el núcleo duro del programa derivista cambiara. En la concepción actual, no son los continentes los que se desplazan horizontalmente, sino son las placas tectónicas las que derivan sobre el manto terrestre. Ello implica un cambio en el núcleo duro de la investigación derivista. Lakatos ${ }^{37}$ establece que el núcleo duro de un programa puede abandonarse cuando el programa deja de anticipar hechos nuevos.

La hipótesis del desplazamiento continental fue de nuevo tomada en consideración, dando lugar al desarrollo teórico de la expansión del fondo oceánico y a la teoría de la tectónica de placas. Debemos señalar que la idea del desplazamiento continental era la cuestión clave. Sin embargo, la teoría de la tectónica de placas no implica desplazamiento de los continentes sino de las placas, y ésta es una diferencia ciertamente importante con respecto a la teoría original de Wegener.

La teoría de la deriva continental en su aspecto estructural es más compatible con la perspectivas de Lakatos, o Laudan ${ }^{38}$, que con la sugerencia de $\mathrm{Kuhn}^{39}$ de un paradigma monopólico durante el periodo de ciencia normal. Si bien se puede argumentar, de acuerdo con Kuhn, que las ciencias de la Tierra estuvieron en una etapa revolucionaria, con paradigmas en competencia, este estado perduró por cincuenta años e incluyó un significativo progreso científi-

\footnotetext{
36 FrANKel, H. (1979).

37 LAKATOS, I. (1983).

38 LAUDAN, R. (1986), El progreso y sus problemas, Madrid, Encuentro Ediciones.

39 KuHN, T.S. (1970), La estructura de las revoluciones cientificas, Méjico, Fondo de Cultura Económica.
} 
co. Laudan enfatiza tanto los problemas empíricos como los conceptuales, lo que parece más apropiado que el énfasis que da Lakatos a las soluciones empíricas, esto es, porque muchos de los opositores subrayan la incompatibilidad conceptual entre la deriva, el manto rígido y la expansión del fondo oceánico, no evidenciándose la tolerancia que Lakatos sugiere para extenderse hacia nuevos programas de investigación, al menos entre los norteamericanos ${ }^{40}$.

De acuerdo con Greene ${ }^{41}$, existe también un factor político y sociológico como explicación adicional a la respuesta contra la teoría de la deriva continental: la desintegración del imperio Austro-Húngaro. Este imperio fue el centro de origen de los grandes paleontólogos y paleogeógrafos de la última centuria, una fortaleza de la paleontología no darwiniana. Este centro colapsó con la desintegración política, que implicó una extensa migración, reubicación de los investigadores, pérdida de una red de revistas, profesorado, patrocinio y parte de la tradición de investigación. También implicó la disolución de la mayor comunidad de investigación y la mayor audiencia de paleogeógrafos que habían mapeado, de forma extensa, los continentes para estudios geológicos y biogeográficos. Gran parte de la oposición a la teoría de la deriva continental de Wegener vino de autores británicos y norteamericanos, quienes no fueron sólo hostiles a su hipótesis sino a la tradición paleogeográfica representada por Wegener. La revisión de las citas de Wegener en sus escritos sobre la deriva continental, muestran su abrumadora dependencia de los trabajos paleogeográficos de esta tradición europea, en su momento asociada con la difunta teoría geotectónica de la contracción.

El estudio histórico revela que en el desarrollo de la teoría de la deriva continental de Alfred Wegener intervinieron diversos factores, relacionados entre sí de forma compleja. La aplicación de la metodología de Lakatos, que se restringe a elaborar reconstrucciones con pretensiones de racionalidad, no agota la interpretación. Desde luego es de esperarse que una nueva luz interpretativa sobre la teoría de la deriva continental, de la expansión del fondo oceánico y sobre la tectónica de placas debe surgir desde la perspectiva de la sociología del conocimiento.

40 Stewart, J.A. (1990), Drifting continents \& colliding paradigms. Perspectives on the geoscience revolution, Bloomington e Indianapolis, Indiana University Press.

41 GREENE, M.T. (1985), «Plate tectonics and biogeography in historical perspective», Earth Sci. Hist., 4(2), pp. 93-97. 